\title{
Langenbeck's Archives of Surgery
}

\section{UNPROVEN VALUE OF AUTOTRANSPLANTATION OF NORMAL PARATHYROID TISSUE TO PREVENT PERMANENT HYPOPARATHYROIDISM AFTER TOTAL THYROIDECTOMY \\ --Manuscript Draft--}

\begin{tabular}{|c|c|}
\hline Manuscript Number: & LAOS-D-17-00372 \\
\hline Full Title: & $\begin{array}{l}\text { UNPROVEN VALUE OF AUTOTRANSPLANTATION OF NORMAL PARATHYROID } \\
\text { TISSUE TO PREVENT PERMANENT HYPOPARATHYROIDISM AFTER TOTAL } \\
\text { THYROIDECTOMY }\end{array}$ \\
\hline Article Type: & Review Articles \\
\hline Section/Category: & Endocrine Surgery \\
\hline Keywords: & Thyroidectomy; parathyroid autotransplantation, hypoparathyroidism; preservation \\
\hline Corresponding Author: & $\begin{array}{l}\text { Antonio Sitges Serra } \\
\text { Institut Hospital del Mar d'Investigacions Mediques } \\
\text { Barcelona, SPAIN }\end{array}$ \\
\hline \multicolumn{2}{|l|}{$\begin{array}{l}\text { Corresponding Author Secondary } \\
\text { Information: }\end{array}$} \\
\hline Corresponding Author's Institution: & Institut Hospital del Mar d'Investigacions Mediques \\
\hline \multicolumn{2}{|l|}{$\begin{array}{l}\text { Corresponding Author's Secondary } \\
\text { Institution: }\end{array}$} \\
\hline First Author: & Antonio Sitges Serra \\
\hline \multicolumn{2}{|l|}{ First Author Secondary Information: } \\
\hline \multirow[t]{3}{*}{ Order of Authors: } & Antonio Sitges Serra \\
\hline & Leyre Lorente-Poch \\
\hline & Juan Sancho \\
\hline \multicolumn{2}{|c|}{ Order of Authors Secondary Information: } \\
\hline \multicolumn{2}{|l|}{ Funding Information: } \\
\hline Abstract: & $\begin{array}{l}\text { Careful parathyroid gland dissection and in situ preservation was the time-honored } \\
\text { approach to prevent parathyroid failure after total thyroidectomy. The relative success } \\
\text { of parathyroid autotransplanttaion of hyperplastic parathyroid tissue in patients with } \\
\text { renal or hereditary hyperparathyroidism did popularize the use of normal parathyroid } \\
\text { tissue autografts during thyroidectomy to prevent permanent hypoparathyroidism. } \\
\text { Proof of autograft function in this setting, however, is controversial as well as its ability } \\
\text { to diminish the hypoparathyroidism rates. Both, studies based on peripheral and on } \\
\text { forearm iPTH sampling cast doubts about its contribution to hormonal sufficiency. } \\
\text { Proofs are accumulating that parathyroid autografts not only increase the rate of } \\
\text { postoperative hypocalcemia but may also be involved in cases of permanent } \\
\text { hypoparathyroidism. This review aims at reviewing critically the current status of } \\
\text { parathyroid autotransplantation during total thyroidectomy. }\end{array}$ \\
\hline
\end{tabular}


UNPROVEN VALUE OF AUTOTRANSPLANTATION OF NORMAL PARATHYROID TISSUE TO PREVENT PERMANENT HYPOPARATHYROIDISM AFTER TOTAL THYROIDECTOMY

\author{
Antonio Sitges-Serra ${ }^{1}$, Leyre Lorente-Poch ${ }^{1}$, Juan Sancho ${ }^{1}$ \\ Endocrine Surgery Unit, Hospital del Mar, Barcelona, Spain
}

Address for correspondence:

Prof. A. Sitges-Serra

Department of Surgery

Hospital del Mar

PasseigMarítim 25-29

08003 Barcelona, Spain

E-mal: asitges@hospitaldelmar.cat

Telephone: +34 932483208 
Parathyroid autotransplantation should not be used as a means of avoiding dissection no matter how long or tedious. Henry JF, Ann Chir 1990

\begin{abstract}
Careful parathyroid gland dissection and in situ preservation was the time-honored approach to prevent parathyroid failure after total thyroidectomy. The relative success of parathyroid autotransplanttaion of hyperplastic parathyroid tissue in patients with renal or hereditary hyperparathyroidism did popularize the use of normal parathyroid tissue autografts during thyroidectomy to prevent permanent hypoparathyroidism. Proof of autograft function in this setting, however, is controversial as well as its ability to diminish the hypoparathyroidism rates. Both, studies based on peripheral and on forearm iPTH sampling cast doubts about its contribution to hormonal sufficiency. Proofs are accumulating that parathyroid autografts not only increase the rate of postoperative hypocalcemia but may also be involved in cases of permanent hypoparathyroidism. This review aims at reviewing critically the current status of parathyroid autotransplantation during total thyroidectomy.
\end{abstract}

\title{
INTRODUCTION
}

Since total thyroidectomy was adopted widely at the end of the last century as a preferred surgical technique for most patients with thyroid cancer or bilateral benign disease, endocrine surgeons have become progressively aware of the fact that it carries a substantial risk of injury to the parathyroid glands, often translating into acute or chronic postoperative parathyroid failure due to low or undetectable iPTH serum concentration. There are three main reasons why the iPTH serum concentration fall below reference values shortly after total thyroidectomy in a significant number of patients: inadvertent parathyroidectomy, autotransplantation (PAT) and parathyroid devascularization. Eventually, all three circumstances may occur in the same patient, particularly after extensive operations performed for advanced/recurrent thyroid malignancies or big goiters, even if thyroidectomy is performed by an experienced surgeon [1]. 
The prevalence of permanent hypoparathyroidism was consistently underestimated until around the year 2000. Multicentre and registry studies published during the last two decades have reported data closer to the day to day reality. As an example, in the collaborative study on thyroidectomy for cancer of the American College of Surgeon Comission on Cancer Patient Care evaluation and the German Thyroid Cancer Study Group, permanent hypoparathyroidism was diagnosed in $10 \%$ of the patients despite not all of them were treated with total thyroidectomy with or without lymphadenectomy [2]. A 25\% rate of permanent hypoparathyroidism was reported in a prospective observational multicentre European study on surgery for differentiated thyroid cancer [3], similar to that observed in a random sample of total thyroidectomy patients cared for in a Polish endocrinological clinic [4]. Rates of permanent hypoparathyroidism of $19 \%$ and $8 \%$ after total thyroidectomy for papillary cancer, with or without prophylactic neck dissection, have been published from a high-volume Italian institution [5]. Unfortunately, none of these reports document the PAT and inadvertent parathyroidectomy rates which are the main reasons underlying postoperative hypocalcemia and permanent parathyroid failure [6].

The functionality of PAT has received little attention despite it is being used liberally and even routinely in many endocrine surgery units. It has been assumed widely and rather uncritically, that the transplantation of normal parathyroid tissue may not only be active but also afford protection against permanent hypoparathyroidism. This is why this narrative review focuses on the need for a reappraisal of the supposed value of the autotransplantation of normal parathyroid tissue to prevent or reduce the permanent hypoparathyroidism rates after total thyroidectomy.

\section{HISTORICAL NOTES}

The autotransplantation of 1-2 parathyroids did not provide protection against permanent hypoparathyroidism, while autotransplantation of 3-4 glands could do this. Alveryd A, Acta Chir Scand 1968

\section{The classical conservative approach}


Traditional teaching in thyroid surgery during the 60's and 70's emphasized the importance of preserving the parathyroid gland blood flow and leaving the glands in situ. In his seminal paper on the surgical technique of thyroidectomy, Norman Thompson wrote: Preservation of parathyroid gland supply is extremely important during total lobectomy [7]. Of the same opinion was Charles Proye who, a few years later, wrote that to prevent postoperative hypoparathyroidism, a painstaking dissection of parathyroid blood supply seems more promising and effective than routine autotransplantation of the glands [8]. These recommendations were meant also to avoid inadvertent resection of the parathyroid glands that, even today, continues to be a major challenge, particularly after node dissection in compartment VI [9-11].

\section{The pioneers of PAT}

Frank Lahey is commonly cited as the pioneer of PAT during thyroidectomy in humans [12] in the years when total thyroidectomy was seldom, if ever, performed. Alveryd [13] performed careful anatomical studies of the parathyroid glands in the late 60's and did advocate PAT using the whole gland intramuscular implantation technique. In his initial report, however, 7/32 patients undergoing PAT (one or more glands) developed permanent hypoparathyroidism. Four-gland autotransplantation afforded some benefit compared to fewer transplanted glands.

The modern era of PAT was initiated by the seminal work of Wells et al. $[14,15]$ describing normal parathyroid function after total parathyroidectomy for renal or multigland primary hyperparathyroidism, with forearm implantation of parathyroid tissue fragments. It is worth noting that in these reports, diseased parathyroid tissue was implanted. It is difficult to understand why the relative functional success of hyperplastic tissue grafting was uncritically and enthusiastically extrapolated to PAT of normal parathyroid glands. Whatever the reasons, several groups adopted a policy of (very) liberal and even routine use of PAT [16-19] and this technique was incorporated to the armamentarium of thyroidectomy despite hard evidence for its ability to prevent permanent hypoparathyroidism was and is still lacking. In fact, the same groups that advocated a liberal PAT policy have published recently data suggesting that they are no longer in favor of such radical approach [20-22]. 


\section{THE CRISIS AND OUR CONTRIBUTIONS}

Despite several methodological flaws, the 1998 paper by the Lille group on factors predicting permanent hypoparathyroidism [23], initiated a critical review of PAT outcomes. These authors wrote: ... patients carried a high risk for permanent hypoparathyroidism if <3 parathyroid glands were preserved in situ during surgery or the early serum parathyroid hormone level was $\leq 12 \mathrm{pg} / \mathrm{ml}$ and the delayed serum calcium levels $\leq 8 \mathrm{mg} / \mathrm{dl}$.

We did approach the issue of the clinical significance of PAT using the fragmented Wells' technique from two angles: 1 ) investigating the impact of the number parathyroid glands remaining in situ (PGRIS), according to the formula 4 - (excised PGs + autotransplanted PGs), on short and long-term parathyroid function; and 2) comparing the rate of parathyroid failure syndromes in PGRIS 3 patients in whom the fourth gland had been either autotransplanted or accidentally excised.

A first study was focused on patients with protracted (1-month) hypoparathyroidism [24]. We did confirm previous findings from the Lille group: patients with PAT had a worse postoperative and 1-month parathyroid function outcomes than those not autografted. In situ gland preservation and delayed (1-month) high-normal serum calcium concentration were key factors predicting recovery of the parathyroid function. The latter was associated with higher calcium and calcitriol, dosages at the time of hospital discharge.

In a second study [6] total thyroidectomy patients were classified in three groups (PGRIS 1-2, PGRIS 3 and PGRIS 4). Patients were followed up in our unit until parathyroid function was restored or the diagnosis of permanent hypopaparhyroidism was made after at least one-year follow-up using standardized definitions [25]. Those patients with fewer glands remaining in situ had worse short and long-term parathyroid function outcomes (Table 1). Specifically, the rate of permanent hypoparathyroidism in 143 patients undergoing PAT was higher than that observed in 514 patients not autografted (9.8 vs. 3.1\%; $\mathrm{P}<0.002)$.

In a third study [26], PGRIS 3 patients were divided in two clinically and surgically similar groups: one in which the fourth gland had been autotransplanted into the 
ipsilateral sternocleidomastoid muscle and another in which the fourth gland had been inadvertently resected. As can be seen in Figure 1, the rates of immediate, protracted (1-month) and permanent parathyroid failure were the same independently of whether the fourth gland was autotransplanted or inadvertently sent to the Pathology lab.

\section{ABSENCE OF PROOF OF CLINICALLY SIGNIFICANT GRAFT FUNCTION}

It remains hard to prove that autotransplanted normal parathyroid tissue takes well into a muscle or subcutaneous pocket and that is functional and able to reduce the permanent hypoparathyroidism rates. The presence of other potentially functioning glands remaining in situ after thyroidectomy and the absence of a clear-cut proof of function due to impossibility of venous sampling close to the sternocleidomastoid muscle, have obscured the benefits of PAT and have been a serious theoretical obstacle for those claiming a benefit.

Most initial studies on PAT function were based on serum calcium and PPTH concentrations in peripheral blood [17,27-29]. This is, however, a rather unreliable method since in these reports inadvertent parathyroidectomy, parathyroid identification or the number of glands remaining in situ were not considered as relevant factors influencing iPTH concentrations and permanent hypoparathyroidism rates. Lo et al. [27] claimed a reduction of permanent hypoparathyroidism rate in PAT patients but their non-PAT patients had a threefold rate of inadvertent parathyroidectomy compared to that of PAT cases. According to their paper's abstract, Kikumori et al. [29] performed total parathyroidectomy plus four gland PAT and total thyroidectomy for thyroid cancer in 86 patients. Careful reading of this report, however, reveals that only 33/86 patients received four-gland PAT and 20/86 no PAT at all (incidentally found cancer in multinodular goiters). The best iPTH serum concentrations were observed in patients in whom the parathyroid glands were preserved in situ. PAT of four glands resulted in no case of permanent hypoparathyroidism. Patients with 2 or 3 glands transplanted had a $17 \%$ and $3 \%$ hypoparathyroidism rates respectively. As already suggested by Alveryd [13], only 
four-gland PAT afforded protection against permanent hypoparathyroidism. This would also fit with the initial proposal of Sam Wells' group to add total parathyroidectomy and four-gland PAT to preventive total thyroidectomy for MEN, a policy that has now been abandoned in favor of in situ preservation [20]. Supporters of PAT assume that normal parathyroid tissue takes well on a muscular bed [30] but solid proof for that is lacking. Fibrosis replacing much of the autografted parathyroid tissue was already reported in 1 out of 3 cases that were studied histologically by Alveryd [13]. El-Sharaki et al. [31] performed graft biopsies on three patients with forearm PAT for electron microscopy studies after subtotal thyroidectomy. Their findings of "reversible degenerative insult at 1 week", however, are difficult to interpret as well as those at 2 weeks when "parathyroid cells showed features of regeneration and activity". No functional correlation was reported. A first attempt to demonstrate function of forearm PAT was made by Sierra et al. [32] They performed a forearm PAT in 12 patients undergoing different types of thyroidectomies and reported as functioning those grafts resulting in a $>1.5$ gradient of iPTH serum concentration between the grafted and the non-grafted forearm. In two patients there was no iPTH gradient. In functioning grafts, a peak gradient of 12.7:1 was observed at 4 weeks falling thereafter to a $4: 1$ gradient at six months. The authors omit giving the actual iPTH concentrations and claim positive sestamibi scans on the autograft sites that most probably were nonspecific. Lo et al. [30] compared PTH gradient between grafted and non-grafted forearms after PAT in seven patients. Results are difficult to interpret since iPTH reference values were not properly stated due to some confusion between $\mathrm{pmol} / \mathrm{L}, \mathrm{pg} / \mathrm{mL}$ and $\mathrm{ng} / \mathrm{L}$. An iPTH gradient was observed $>1.5$ in 6 out of 7 patients but, according to their Table 2, we suspect that iPTH concentrations in the non-grafted arm at three months were below normal in some patients. Using subcutaneous forearm PAT, Cavallaro et al. [33] documented a significant iPTH gradient (1.5-5) between grafted and non-grafted forearms in $48 \%$ of patients 1 week after surgery, $88 \%$ after one month and $96 \%$ (24 out of 25 patients) 3 months after surgery, but failed to properly document long-term parathyroid function. The Casanova test [35] was not performed in neither of these two gradient studies; therefore, it remains difficult to quantify the contribution of PAT to peripheral blood iPTH concentrations. 
A sensible interpretation of most reports claiming functionality of PAT is that although some endocrine function from grafted parathyroid fragments may be detectable, it does not follow that it is enough to prevent permanent hypoparathyroidism.

\section{TECHNICAL VARIATIONS}

The most commonly used technique for PAT is implantation of the fragmented gland into pockets on the ipsilateral sternocleidomastoid muscle. This can be done immediately after gland excision or after a period of cooling in cold saline. An European survey revealed that this technique is currently used by over $80 \%$ of the endocrine surgeons [35] and it seems highly unlikely that differences in specific phases of the PAT process could substantially modify its long-term function [26].

Gauger et al. [36] explored an alternate PAT technique comparing the injection of dispersed parathyroid tissue into the ipsilateral sternocleidomastoid muscle with the standard fragmented technique. They found no differences in terms of long-term iPTH concentrations. The study, however, is flawed by the lack of a control non-autografted group and failure to obtain iPTH measurements in $25 \%$ of their patients.

\section{THE PSYCHOLOGICAL VARIABLES: COLOR CHANGE, ANGIOGRAPHY AND SURGEON'S FEES}

The threshold for PAT is highly subjective except in cases where glands have been completely isolated from surrounding tissues or inadvertently excised and found in the specimen before it is sent to the Pathology lab. Other than this, the indication of PAT lays on a grey zone. We suspect that, independently of the appearance or the more or less firm attachment of the glands to surrounding structures, those surgeons convinced of the efficacy of PAT adopt a more liberal (even routine) transplantation policy compared to more skeptical surgeons. PAT of discolored glands (or of the most discolored one) has been widely adopted. A study by Promberger et al. [37], however, 
suggests that transplanting discolored glands gives worse results that leaving them in situ. This would support the concept that PAT based on color changes does not afford a functional advantage and, in fact, may result in worse long-term parathyroid function. Furthermore, change in color cannot be used as a reliable marker of parathyroid dysfunction. Lang et al. [38] reported a higher rate of permanent hypoparathyroidism in cases in which no color change was detected in any of the four parathyroid glands than in cases where discoloration of one or two glands was noticed. Reduced or absence of vascular supply as determined by green indocyanine fluorescence angiography [39] has been proposed to determine when a (non-perfused) parathyroid gland should be transplanted. This implies, however, that the authors rely on PAT rather than on meticulous dissection. It also implies that the possibility of parathyroid gland revascularization after the wound is closed is not considered. This is not consistent with the fact that recovery of the parathyroid function is a dynamic, long-standing process [40]. In addition, interpretation of the parathyroid function data in this study is hampered because four glands were identified in only $4 / 36$ patients and all subjects received routine calcium and vitamin D supplementation after thyroidectomy. Another study on parathyroid gland angiography found a poor (in fact, non-existent) correlation between impaired parathyroid blood flow and postoperative parathyroid function [41]. Our guess is that intraoperative angiography will never match iPTH measurements 4-6 hours following thyroidectomy as predictor of parathyroid failure. In addition, selecting the less perfused glands for PAT may not be the appropriate solution.

Last but not least, it should be mentioned that in the USA (perhaps in other countries too) surgeons and/or the institutions they work in, charge a fee of up to $1000 \$$ if PAT is performed during total thyroidectomy [42]. This conflict of interest probably influences PAT rates favoring a liberal -if not routine- and uncritical PAT policies. It may also interfere with scientific publishing. In addition, PAT may be further encouraged by pathologists if a frozen biopsy is taken before autotransplantation for histological verification.

\section{CONCLUSION}


Normal parathyroid gland autotransplantation is currently regarded more critically than in the past two decades. Detailed scrutiny of the available literature reveals that hard evidence supporting its role in preventing permanent hypoparathyroidism is lacking. On the other hand, more data are accumulating on the benefits of leaving the parathyroid glands wellvascularized in situ. Endocrine surgeons are urged to improve their technical skills and anatomical knowledge to better identify and preserve the parathyroid normal glands when performing thyroidectomy.

Conflicts of interest. The authors declare that they have no conflict of interest.

Ethical approval: This article does not contain any studies with human participants performed by any of the authors. 


\section{REFERENCES}

1. Duclos A, Peix JL, Colin C, Kraimps JL, Menegaux F, Pattou F, Sebag F, Touzet S, Bourdy S, Voirin N, Lifante JC; CATHY Study Group (2012) Influence of experience on performance of individual surgeons in thyroid surgery: prospective cross sectional multicentre study. BMJ 344:d8041.

2. HundahI SA, Cady B, Cunningham MP, Mazzaferri E, McKee RF, Rosai J, Shah JP, Fremgen AM, Stewart AK, Hölzer S (2000) Initial results from a prospective cohort study of 5583 cases of thyroid carcinoma treated in the united states during 1996. U.S. and German Thyroid Cancer Study Group. An American College of Surgeons Commission on Cancer Patient Care Evaluation study. Cancer 89:202-217.

3. Vrachimis A, Wenning C, Gerß J, Dralle H, Vaez Tabassi M, Schober O, Riemann B; MSDS study group (2015) Not all DTC patients with N positive disease deserve the attribution "high risk". Contribution of the MSDS trial. J Surg Oncol 112:9-14.

4. Nawrot I, Pragacz A, Pragacz K, Grzesiuk W, Barczyński M (2014) Total thyroidectomy is associated with increased prevalence of permanent hypoparathyroidism Med Sci Monit 20:1675-1681.

5. Viola D, Materazzi G, Valerio L, Molinaro E, Agate L, Faviana P, Seccia V, Sensi E, Romei C, Piaggi P, Torregrossa L, Sellari-Franceschini S, Basolo F, Vitti P, Elisei R, Miccoli P (2015) Randomized, prospective trial finds no clinical advantage to prophylactic central-neck dissection for papillary thyroid cancer. J Clin Endocrinol Metab 100:1316-1324.

6. Lorente-Poch L, Sancho JJ, Ruiz S, Sitges-Serra A (2015) Importance of in situ preservation of parathyroid glands during total thyroidectomy. Br J Surg 102:359-367.

7. Thompson NW, Olsen WR, Hoffman GL (1973) The continuing development of the technique of thyroidectomy Surgery 73:913-927.

8. Proye C, Maes B, Bondil P, Vanseymortier L, Lagache G (1982) Parathyroid risk in thyroid surgery (In French). J Chir 119:491-498. 
9. Sitges-Serra A, Gallego-Otaegui L, Suárez S, Lorente-Poch L, Munné A, Sancho JJ (2017) Inadvertent parathyroidectomy during total thyroidectomy and central neck dissection for papillary thyroid carcinoma. Surgery 161:712-719.

10. Ondik MP, McGinn J, Ruggiero F, Kim SW, Chung KW, Youn YK (2009) Unintentional parathyroidectomy and hypoparathyroidism in secondary central compartment surgery for thyroid cancer. Head Neck 32:462-6.

11. Applewhite MK, White MG, Xiong 3, Pasternak JD, Abdulrasool L, Ogawa L, Suh I, Gosnell JE, Kaplan EL, Duh QY, Angelos P, Shen WT, Grogan RH (2016) Incidence, risk factors, and clinical outcomes of incidental parathyroidectomy during thyroid surgery. Ann Surg Oncol 23:4310-4315.

12. Lahey FH. Transplantation of the parathyroids in partial thyroidectomy (1926) Surg Gynecol Obstet 62:508-509.

13. Alveryd A. Parathyroid glands in thyroid surgery (1968) I. Anatomy of parathyroid glands. II. Postoperative hypoparathyroidism - identification and autotransplantation of parathyroid glands. Acta Chir Scand 389:1-120.

14. Wells SA, Ellis GJ, Gunnells JC, Schneider AB, Sherwood LM (1976) Parathyroid autotransplantation in primary parathyroid hyperplasia. N Engl J Med 295:5762.

15. Wells SA, Gunnells JC, Shelburne JD, Schneider AB, Sherwood LM (1975) Transplantation of the parathyroid glands in man: clinical indications and results. Surgery 78:34-44.

16. Paloyan E, Lawrence AM, Paloyan D (1977) Successful autotransplantation of the parathyroid glands during total thyroidectomy for carcinoma. Surg Gynecol Obstet 145:364-368.

17. Olson Jr., JA, DeBenedetii MK, Baumann DS, Wells SA, Jr. (1996) Parathyroid autotransplantation during thyroidectomy. Ann Surg 223:472-480.

18. Zedenius J, Wadstrom C, Delbridge L (1999) Routine autotransplantation of at least one parathyroid gland during total thyroidectomy may reduce permanent hypoparathyroidism to zero. Aust N Z J Surg 69:794-797.

19. Lo CY, Lam KY (2001) Routine parathyroid autotransplantation during thyroidectomy. Surgery 129:318-323. 
20. Moley JF, Skinner M, Gillanders WE, Lairmore TC, Rowland KJ, Traugott AL, Jin LX, Wells SA Jr. (2015) Management of the parathyroid glands during preventive thyroidectomy in patients with Multiple Endocrine Neoplasia Type 2. Ann Surg 262:641-646.

21. Prichard RS, Edhouse PJ, Sidhu SB, Sywak MS, Delbridge L (2011) Post-operative partial hypoparathyroidism: an under-recognized disorder. ANZ J Surg 81:524527.

22. Lang BH, Chan DT, Chow FC (2016) Visualizing fewer parathyroid glands may be associated with lower hypoparathyroidism following total thyroidectomy. Langenbecks Arch Surg 401:231-238.

23. Pattou F, Combemale F, Fabre S, Carnaille B, Decoulx M, Wemeau JL, Racadot A, Proye C (1998) Hypocalcemia following thyroid surgery: incidence and prediction of outcome. World J Surg 1998; 22:718-24.

24. Sitges-Serra A, Ruiz S, Girvent M, Manjón H, Dueñas JP, Sancho JJ (2010) Outcome of protracted hypoparathyroidism after total thyroidectomy. Br J Surg 97:1687-1695.

25. Lorente-Poch L, Sancho JJ, Muñoz-Nova JL, Sánchez-Velázquez P, Sitges-Serra A (2015) Defining the syndromes of parathyroid failure after total thyroidectomy. Gland Surg 4:82-90.

26. Lorente-Poch L, Sancho J, Muñoz JL, Gallego-Otaegui L, Martínez-Ruiz C, SitgesSerra A (2017) Failure of fragmented parathyroid gland autotransplantation to prevent permanent hypoparathyroidism after total thyroidectomy Langenbeck's Arch Surg 402:281-287.

27. Lo CY, Lam KY, Weber CJ, Shaha AR, Davis O (1998) Postoperative hypocalcemia in patients who did or did not undergo parathyroid autotransplantation during thyroidectomy: A comparative study. Surgery 124:1081-1087.

28. Funahashi H, Satoh Y, Imai T, Ohno M, Narita T, Katoh M, Tanaka Y, Andoh H, Miyazaki K (1993) Our technique of parathyroid autotransplantation in operation for papillary thyroid carcinoma. Surgery 114:92-96.

29. Kikumori T, Imai T, Tanaka Y, Oiwa M, Mase T, Funahashi H (1999) Parathyroid autotransplantation with total thyroidectomy for thyroid carcinoma: Long-term follow-up of grafted parathyroid function. Surgery 125:504-508. 
30. Lo CY, Tam SC (2001) Parathyroid autotransplantation during thyroidectomy: documentation of graft function. Arch Surg 136:1381-1385.

31. El-Sharaky MI, Kahalil MR, Sharaky O, Sakr MF, Fadaly GA, El-Hammadi H, Moussa MM (2003) Assessment of parathyroid autotransplantation for preservation of parathyroid function after total thyroidectomy. Head Neck 25:799-807.

32. Sierra M, Herrera MF, Herrero B, Jiménez F, Sepúlveda J, Lozano RR, Gamino R, González O, Correa-Rotter R (1998) Prospective biochemical and scintigraphic evaluation of autografted normal parathyroid glands in patients undergoing thyroid operations. Surgery 124:1005-1011 .

33. Cavallaro G, lorio O, Centanni M, Porta N, lossa A, Gargano L, Del Duca S, Gurrado A, Testini M, Petrozza V, Silecchia G (2015) Parathyroid reimplantation in forearm subcutaneous tissue during thyroidectomy: A simple and effective way to avoid hypoparathyroidism. World J Surg 39:1936-1942.

34. Casanova D, Sarfati E, De Francisco A, Amado J A, Arias M, Dubost C (1991) Secondary hyperparathyroidism: diagnosis of site of recurrence. World J Surg 15:546-549.

35. Lorente L, Sancho JJ, Sitges-Serra A (2015) European survey of the indications and technique of parathyroid autotransplantation during thyroidectomy. Langenbeck's Arch Surg 400:396 (Abstract).

36. Gauger P, Reeve TS, Wilkinson M, Delbridge LW (2000) Routine parathyroid autotransplantation during total thyroidectomy: the influence of technique. Eur J Surg 166:605-609.

37. Promberger R, Ott J, Kober F, Mikola B, Karik M, Freissmuth M, Hermann M (2010) Intra- and postoperative parathyroid hormone-kinetics do not advocate for autotransplantation of discolored parathyroid glands during thyroidectomy. Thyroid 20:1371-1375.

38. Lang BH, Chan DT, Chow FC, Wong KP, Chang RY (2016) The association of discolored parathyroid glands and hypoparathyroidism following total thyroidectomy. World J Surg 40:1611-1617. 
39. Vidal Fortuny J, Belfontali V, Sadowski SM, Karenovics W, Guigard S, Triponez F (2016) Parathyroid gland angiography with indocyanine green fluorescence to predict parathyroid function after thyroid surgery. Br J Surg 103:537-543.

40. Villarroya-Marquina I, Sancho J, Lorente-Poch L, Gallego-Otaegui L, Sitges-Serra A. Time to parathyroid function recovery in patients with protracted hypoparathyroidism after total thyroidectomy. Eur J Endocrinol (in press).

41. Lang BH, Wong CK, Hung HT, Wong KP, Mak KL, Au KB (2017) Indocyanine green fluorescence angiography for quantitative evaluation of in situ parathyroid gland perfusion and function after total thyroidectomy. Surgery 161:87-95.

42. Savarise M, Senkowski C, eds. (2017). Principles of Coding and Reimbursement for Surgeons. Springer International Publishing, Switzerland. pp. 330-331. 


\section{FIGURE LEGEND}

Figure 1. Parathyroid function outcomes in PGRIS 3 patients after total thyroidectomy (modified from 26) 



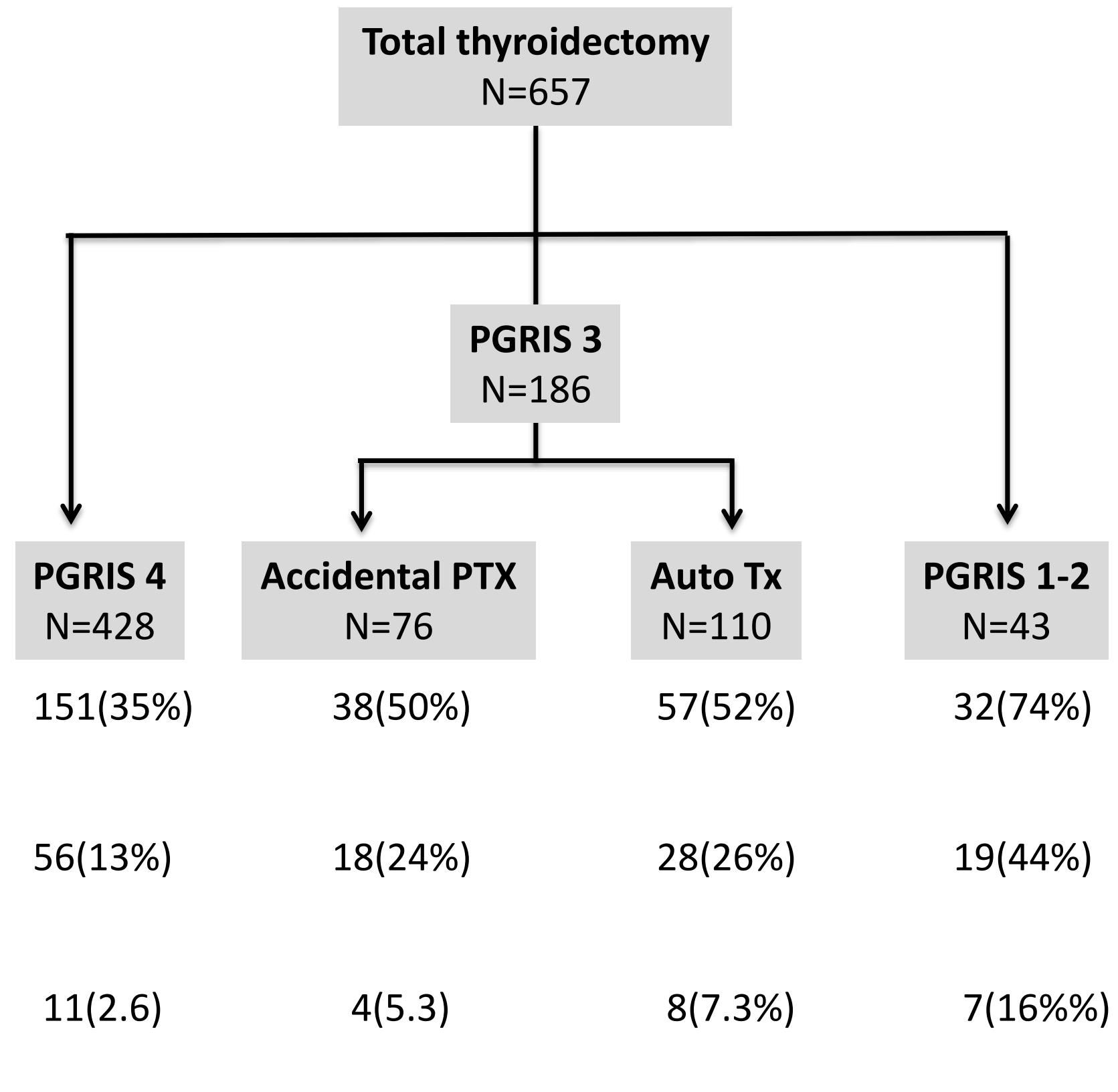

Postoperative (24h) 151(35\%) hypocalcemia

Protracted (1 mo.) hypoparathyroidism

Permanent hypoparathyroidism 
Table 1 Influence of parathyroid glands preserved in situ on the risk of hypocalcemia, hypoparathyroidism, s-Ca and iPTH after total thyroidectomy

\begin{tabular}{|c|c|c|c|c|}
\hline & $\begin{array}{l}\text { PGRIS 1-2 } \\
(\mathrm{N}=43)\end{array}$ & $\begin{array}{l}\text { PGRIS } 3 \\
(\mathrm{~N}=186)\end{array}$ & $\begin{array}{l}\text { PGRIS } 4 \\
(\mathrm{~N}=428)\end{array}$ & $P$ Value \\
\hline $\begin{array}{l}\text { Hypocalcemia }(\mathrm{n}=278) \\
(\mathrm{sCa} 24 \mathrm{~h}<8.0 \mathrm{mg} / \mathrm{dL})\end{array}$ & $32(74)$ & $95(51)$ & $155(36)$ & $<0.0001^{*}$ \\
\hline $\begin{array}{l}\text { Protracted Hypoparathyroidism }(n=121) \\
\text { (iPTH }{ }^{1 \mathrm{~m} 0}<13 \mathrm{pg} / \mathrm{mL} \text { ) }\end{array}$ & $19(44)$ & $46(25)$ & $56(13)$ & $<0.0001^{*}$ \\
\hline $\begin{array}{l}\text { Permanent Hypoparathyroidism ( } n=30) \\
\text { (iPTH }{ }^{1 y<13 ~ p g / m L ~} \pm \text { Ca or Vit.D treatment) }\end{array}$ & $7(16)$ & $12(6.5)$ & $11(2.6)$ & $<0.0001^{*}$ \\
\hline sCa postop ${ }^{24 \mathrm{~h}}$ (mg/dL) & $7.6 \pm 0.9$ & $7.9 \pm 0.8$ & $8.2 \pm 0.8$ & $<0.0001 \dagger$ \\
\hline iPTH 24 h (pg/mL) & $7.4 \pm 7$ & $6.5 \pm 8$ & $24.3 \pm 21$ & $<0.0001 \dagger$ \\
\hline $\mathrm{iPTH}^{1} \mathrm{mo}(\mathrm{pg} / \mathrm{mL})$ & $19.7 \pm 23$ & $28 \pm 25$ & $37 \pm 28$ & $<0.0001 \dagger$ \\
\hline Age (years) & & & & $0.141^{*}$ \\
\hline$\leq 45$ & $12(7)$ & $59(34)$ & $103(59)$ & \\
\hline$>45$ & $31(7)$ & $127(26)$ & $325(67)$ & \\
\hline Sex ratio (M:F) 112/545 & $5: 38$ & $28: 158$ & $79: 349$ & $0.377^{*}$ \\
\hline Extent of surgery & & & & $0.004^{*}$ \\
\hline TT $(n=540)$ & $32(74 \%)$ & $142(76 \%)$ & $366(85.5 \%)$ & \\
\hline $\mathrm{TT}+\mathrm{CCND}(\mathrm{n}=63)$ & $9(21 \%)$ & $25(13 \%)$ & $29(7 \%)$ & \\
\hline $\mathrm{TT}+\mathrm{CCND}+\mathrm{LCND}(\mathrm{n}=54)$ & $2(5 \%)$ & $19(10 \%)$ & $33(8 \%)$ & \\
\hline
\end{tabular}

PGRIS: parathyroid glands preserved in situ; $\mathrm{sCa}^{24 \mathrm{~h}}$ : serum calcium value 24 hours after surgery; $\mathrm{PTTH}^{24 \mathrm{~h}}$ : intact parathyroid hormone at 24 hours after surgery; iPTH $1^{\mathrm{mo}}$ : intact parathyroid hormone at 1 month after surgery; TT: total thyroidectomy; CCND: central compartment node dissection; LCND: lateral compartment node dissection $* \chi^{2}$ test; $†$ One-way ANOVA 


\section{DISCLOSURES}

The authors declare that they do not have conflicts of interest 